\title{
Modernization of Cross Section Library for VVER-1000 Type Reactors Internals and Pressure Vessel Dosimetry
}

\author{
Andrey Voloschenko ${ }^{1}$, Sergey Zaritskiy ${ }^{2, \mathrm{a}}$, Aleksander Egorov ${ }^{2}$, and Viktor Boyarinov ${ }^{2}$ \\ ${ }^{1}$ M.V. Keldysh Institute of Applied Mathematics, 4 Miusskaya sq., Moscow 125047, Russia \\ ${ }^{2}$ National Research Centre Kurchatov Institute, 1 Kurchatov sq., Moscow 123182, Russia
}

\begin{abstract}
The broad-group library BGL1000_B7 for neutron and gamma transport calculations in VVER-1000 internals, RPV and shielding was carried out on a base of fine-group library v7-200n47g from SCALE-6 system. The comparison of the library BGL1000_B7 with the library v7-200n47g and the library BGL1000 (the latter is using for VVER-1000 calculations) is demonstrated on several calculation and experimental tests.
\end{abstract}

\section{Introduction}

Cross section libraries BUGLE-96 [1] and BGL1000 [2] (47 neutron groups and 20 gamma groups) are used at present time for internals and pressure vessel dosimetry calculations of the VVER-1000 reactor types. Those broad-group libraries were developed from fine-group library VITAMIN-B6 [3], which is based on ENDF/B-VI.3 evaluated data files. Since ENDF/B-VII.0 evaluated data files are available the renovation of problem-oriented cross-section libraries is necessary.

Broad-group libraries are necessary first of all for three-dimension calculations, whereas oneand two-dimension calculations can be carried out with fine-group libraries using modern personal computers.

This work aims at the development of a problem-oriented broad-group library on a base of ENDF/BVII.0 files for VVER-1000 dosimetry calculation, i.e. an analogue of the currently used BGL1000 library, which is based on the ENDF/B-VI.3 files.

\section{BGL1000_B7 Library}

At the first stage the broad-group library BGL1000_B7 (417 nuclides, 47 neutron and 20 gamma groups) was compiled starting from ENDF/B-VII based fine-group library v7-200n47g from SCALE-6 [4].

The VVER-1000 model, for which dosimetry calculations the library BGL1000_B7 was developed, is presented on Figs. 1 and 2.

The link CSASI with option PARM=(HALT) from SCALE-6 system was used for fine-group constants preparation; this option allows to prepare cross-section library only for a given composition.

\footnotetext{
${ }^{a}$ Corresponding author: zaritskiy_sm@nrcki.ru
}

This is an Open Access article distributed under the terms of the Creative Commons Attribution License 2.0, which permits unrestricted use, distribution, and reproduction in any medium, provided the original work is properly cited. 


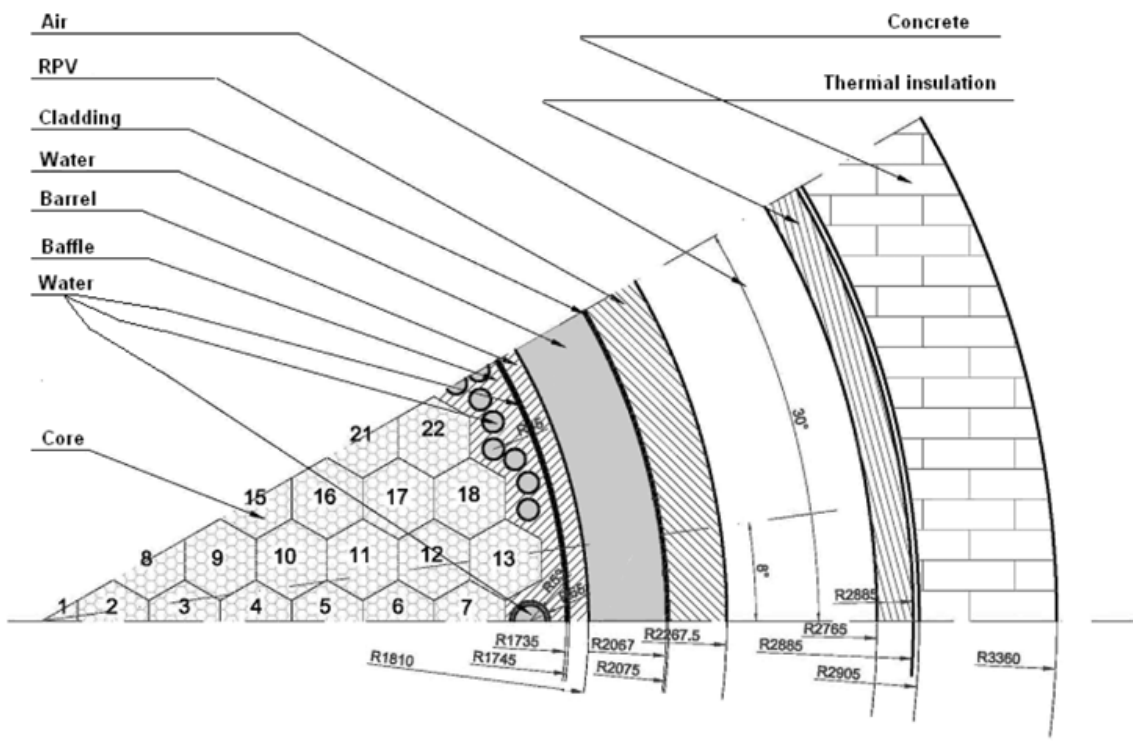

Figure 1. VVER-1000 horizontal cross-section.

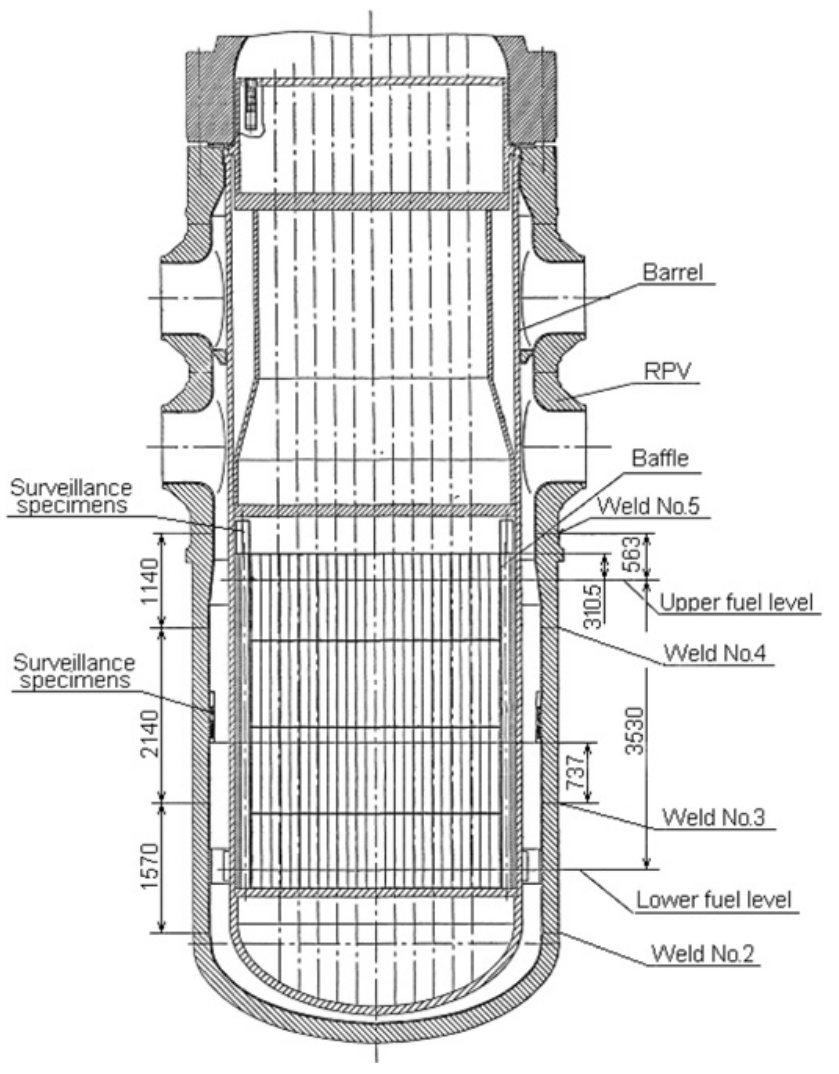

Figure 2. VVER-1000 RPV and internals. 
Table 1. 1D VVER-1000 model for library BGL1000_B7 preparing.

\begin{tabular}{|c|c|c|c|c|c|c|}
\hline \multirow{2}{*}{ Parameter } & \multicolumn{7}{|c|}{ Material } \\
\cline { 2 - 8 } & Core & Baffle & Water 1 & Barrel & Water 2 & Cladding \\
\hline T, K & $* / 300$ & $575 / 300$ & $571 / 300$ & $568 / 300$ & $565 / 300$ & $561 / 300$ \\
\hline R out, cm & 158.2 & 173.5 & 174.5 & 181.0 & 206.8 & 207.5 \\
\hline N meshes & 53 & 19 & 2 & 11 & 29 & 2 \\
\hline \multirow{2}{*}{ Parameter } & RPV & Air 1 & Therm. ins. & Air 2 & Concrete & \\
\cline { 2 - 8 } & $561 / 300$ & $523 / 300$ & $343 / 300$ & $341 / 300$ & $340 / 300$ & \\
\hline T, K & 276.5 & 288.5 & 290.5 & 300.0 & \\
\hline R out, cm & 226.8 & 27.5 & 4 & 15 & \\
\hline N meshes & 36 & 26 & 16 & 4 & \\
\hline
\end{tabular}

* $855 \mathrm{~K}$ for fuel, $633 \mathrm{~K}$ for fuel cladding.

Resonance self-shielding treatment was done by Bondarenko method with module BONAMI. Crosssections were prepared for reactor operating temperatures and for $300 \mathrm{~K}$.

The 1D VVER-1000 model calculation was carried out using prepared fine-group cross-sections in $\mathrm{P}_{5} \mathrm{~S}_{1} 6$ approximation with the code ROZ-6.6 created in KIAM [5]. The more detailed space grid than in [2] was used with space meshes decreasing close to boundaries between different materials. The iteration convergence criterion was equal to $10^{-4}$ and neutron thermalization was taken into account. Parameters of the 1D model (which corresponds to models Figs. 1 and 2) are presented in the Table 1.

The spectra averaged for different materials and temperatures were prepared using the obtained fine-group solution. Those spectra were used in the SCALE-6 system for the generation of broad-group cross-sections from fine-group ones.

In addition to self-shielded broad-group cross-sections non-shielded cross-sections for all 417 nuclides from v7-200n47g library averaged with spectrum in air behind RPV were prepared.

So in comparison with the BGL1000 library the updated nuclear data base and a more detail 1D model for data collapsing were used for the library BGL1000_B7 preparation.

Several calculations were carried out for the library BGL1000_B7 testing and compared with the v7-200n47g and BGL1000 libraries:

- comparative calculations of the VVER-1000 1D model with different libraries,

- calculations of neutron spectra and dosimetry reaction rates, which were measured in representative regions of VVER-1000 mock-up on the reactor LR-0 [6],

- calculations of dosimetry reaction rates, which were measured on the outer surface of the RPV of Balakovo-2, Balakovo-3, and Kalinin-1 VVER-1000.

Some results of listed calculations are presented below.

\section{Calculations of VVER-1000 1D Model}

Calculations of 1D model (Table 1) were carried out with v7-200n47g, BGL1000_B7, and BGL1000 libraries. All libraries include thermalization scattering matrices. $\mathrm{P}_{5} \mathrm{~S}_{16}$ approximation, detailed space grid, convergence criterion of $10^{-4}$ for inner iterations and $10^{-3}$ for iterations in thermalization region were used in calculations by the code ROZ-6.6 [5]. In this case the uncertainty of the model calculation results is less than $1 \%$.

The fission spectrum from SCALE-6 was used as the core source spectrum. The source space distribution in the core was specified as constant. Calculation results are presented in the Table 2, where deviations from fine-group calculation are shown for neutron fluxes calculated with BGL1000_B7 and BGL1000. 
Table 2. Libraries comparison for 1D VVER-1000 model.

\begin{tabular}{|l|l|l|l|l|l|l|l|}
\hline \multirow{2}{*}{ Library } & \multirow{2}{*}{ Parameter } & \multicolumn{5}{|c|}{ Neutron energy } \\
\cline { 3 - 7 } & & $>3.0 \mathrm{MeV}$ & $>1.0 \mathrm{MeV}$ & $>0.5 \mathrm{MeV}$ & $>0.1 \mathrm{MeV}$ & $<0.414 \mathrm{eV}$ \\
\cline { 3 - 7 } & & \multicolumn{5}{|c|}{ RPV inner surface } \\
\hline v7-200n47g & Neutron flux, $\mathrm{cm}^{-2} \mathrm{~s}^{-1}$ & $6.04 \mathrm{E}+09$ & $2.11 \mathrm{E}+10$ & $3.25 \mathrm{E}+10$ & $4.88 \mathrm{E}+10$ & $4.17 \mathrm{E}+10$ \\
\hline BGL1000_B7 & Deviation, \% & -1.3 & -1.3 & -1.2 & -0.6 & -4.3 \\
\hline BGL1000 & Deviation, \% & -5.1 & -3.7 & -3.3 & -2.4 & -8.7 \\
\hline Library & Parameter & \multicolumn{5}{|c|}{ RPV outer surface } \\
\hline v7-200n47g & Neutron flux, $\mathrm{cm}^{-2} \mathrm{~s}^{-1}$ & $2.17 \mathrm{E}+08$ & $1.60 \mathrm{E}+09$ & $5.02 \mathrm{E}+09$ & $1.23 \mathrm{E}+10$ & $1.12 \mathrm{E}+09$ \\
\hline BGL1000_B7 & Deviation, \% & -1.5 & -0.7 & -1.5 & -0.4 & -0.9 \\
\hline BGL1000 & Deviation, \% & -5.2 & -3.1 & -4.7 & -3.2 & -3.6 \\
\hline
\end{tabular}

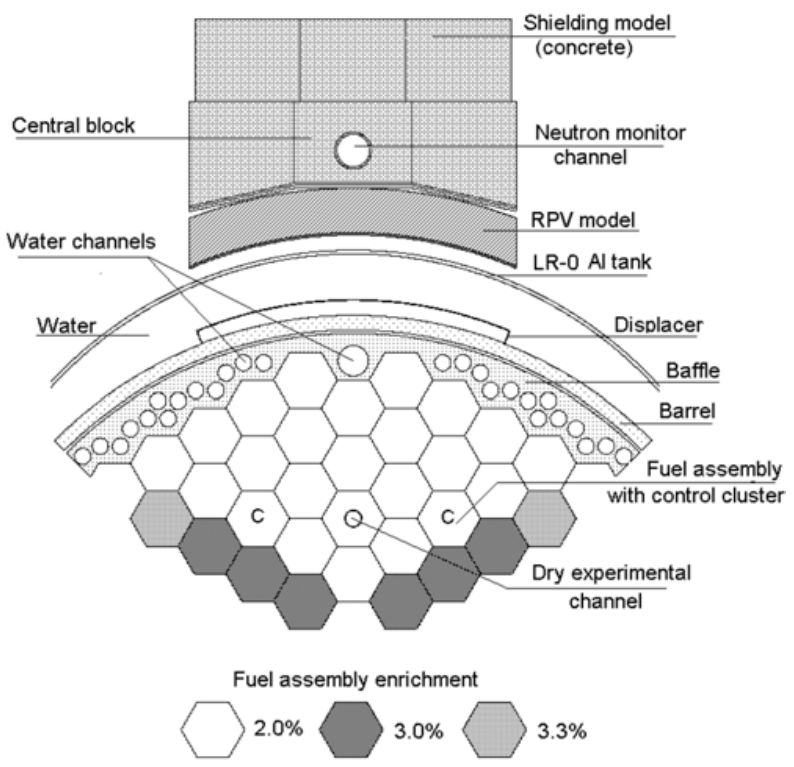

Figure 3. The layout of the VVER-1000 mock-up on the reactor LR-0 (top view).

The deviations between the neutron fluxes calculated with the BGL1000_B7 and the v7-200n47g libraries are caused by the neutron data collapsing only. In case of calculation with the BGL1000 library the deviations with the v7-200n47g results are higher because the ENDF/B-VI.3 files and a less detailed 1D model were used for data collapsing. Comparison of the deviations values demonstrates the effect of the use of the modern data files and improved 1D model for broad-group constants collapsing.

\section{Calculations of VVER-1000 Mock-up on LR-0 Reactor}

Calculations of the values measured in the VVER-1000 mock-up on the LR-0 reactor [6] were carried out by the code KATRIN 2.0 [5] with v7-200n47g, BGL1000_B7, and BGL1000 libraries.

The layout of the VVER-1000 mock-up on the reactor LR-0 is presented in Fig. 3.

The comparison of measured and calculated neutron spectra on the outer surface of barrel, inner and outer surfaces of RPV is shown in the Fig. 4.

Spectral indices and attenuation factors are compared in the Tables 3 and 4. Spectral index is defined as the ratio of the integral neutron flux values over different energy thresholds (in this case - over 0.5, 1.0 , and $3.0 \mathrm{MeV}$ ). The attenuation factor is defined as the ratio of the integral neutron flux values in 


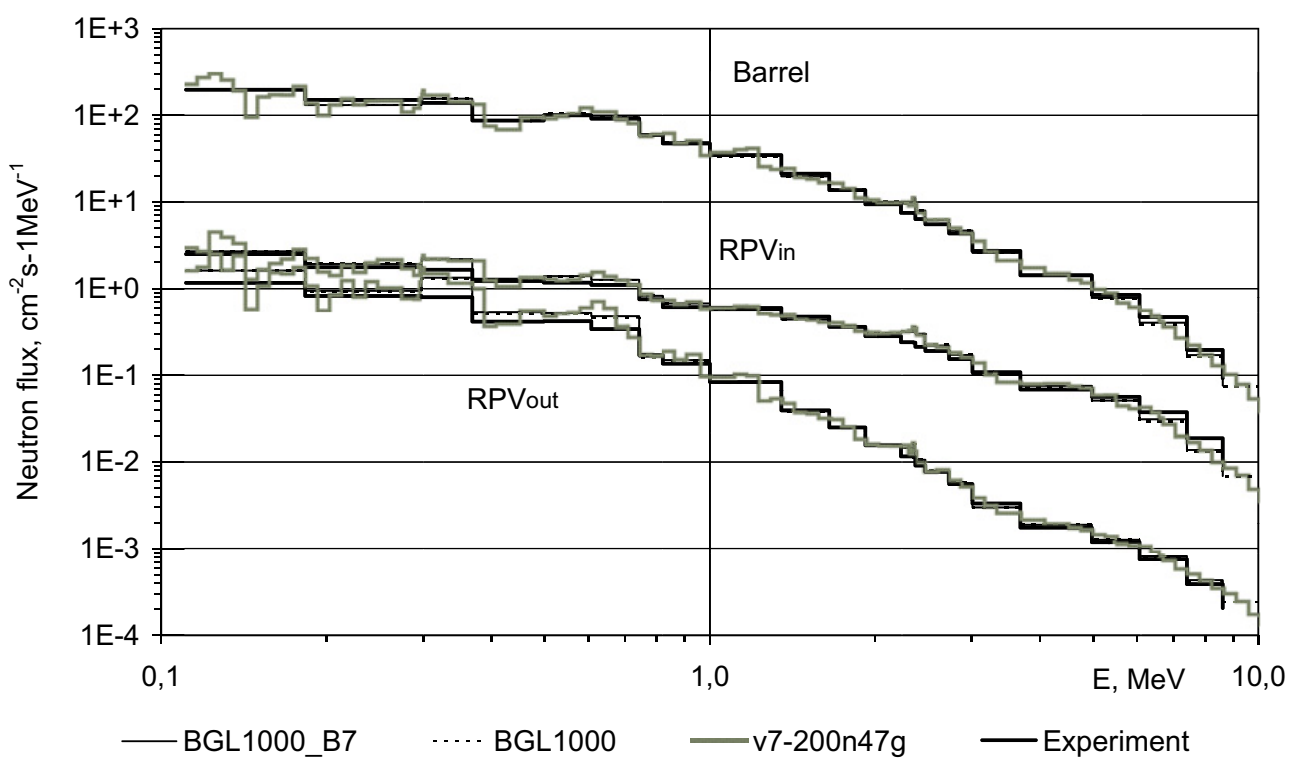

Figure 4. Measured and calculated fast neutron spectra in the VVER-1000 mock-up (normalization to the integral over $1.0 \mathrm{MeV}$ on the RPV inner surface).

Table 3. Comparison of measured and calculated spectral indices (SI) in VVER-1000 mock-up.

\begin{tabular}{|l|l|l|l|l|l|}
\hline \multirow{2}{*}{ Spectral index } & \multirow{2}{*}{ Point } & \multirow{2}{*}{ Measurement } & \multicolumn{3}{|c|}{ C/M for Libraries } \\
\cline { 4 - 7 } & & & v7-200n47g & BGL1000_B7 & BGL1000 \\
\hline \multirow{3}{*}{ SI 0.5/3.0 } & Barrel & $12.7 \pm 2.6 \%$ & 1.07 & 1.06 & 1.08 \\
\cline { 2 - 6 } & RPVin & $4.60 \pm 2.5 \%$ & 1.10 & 1.10 & 1.12 \\
\cline { 2 - 6 } & RPVout & $25.8 \pm 2.6 \%$ & 1.10 & 1.11 & 1.11 \\
\hline \multirow{3}{*}{ SI 1.0/3.0 } & Barrel & $6.25 \pm 1.7 \%$ & 1.04 & 1.04 & 1.06 \\
\cline { 2 - 6 } & RPVin & $3.18 \pm 1.3 \%$ & 1.06 & 1.06 & 1.07 \\
\cline { 2 - 6 } & RPVout & $8.71 \pm 2.0 \%$ & 0.94 & 0.95 & 0.96 \\
\hline
\end{tabular}

Table 4. Comparison of measured and calculated attenuation factors (AF) in VVER-1000 mock-up.

\begin{tabular}{|l|c|l|l|l|l|}
\hline \multirow{2}{*}{ Attenuation factor } & \multirow{2}{*}{$\mathrm{E}, \mathrm{MeV}$} & \multirow{2}{*}{ Measurement } & \multicolumn{3}{|c|}{ C/M for Libraries } \\
\cline { 4 - 7 } & $>0.1$ & $59.1 \pm 3.2 \%$ & 0.98 & 0.97 & 1.00 \\
\hline \multirow{4}{*}{ AF Barrel/RPVin } & $>0.5$ & $49.61 \pm 3.3 \%$ & 1.01 & 1.01 & 1.04 \\
\cline { 2 - 6 } & $>1.0$ & $35.12 \pm 3.0 \%$ & 1.03 & 1.04 & 1.07 \\
\cline { 2 - 6 } & $>3.0$ & $18.03 \pm 3.5 \%$ & 1.03 & 1.05 & 1.06 \\
\hline \multirow{5}{*}{ AF RPVin/RPVout } & $>0.1$ & $4.33 \pm 3.4 \%$ & 0.80 & 0.80 & 0.81 \\
\cline { 2 - 6 } & $>0.5$ & $7.33 \pm 3.5 \%$ & 0.86 & 0.86 & 0.87 \\
\cline { 2 - 6 } & $>1.0$ & $15.03 \pm 3.0 \%$ & 0.96 & 0.96 & 0.96 \\
\cline { 2 - 6 } & $>3.0$ & $41.06 \pm 3.3 \%$ & 0.86 & 0.86 & 0.86 \\
\hline
\end{tabular}

different points of the mock-up. The uncertainties of the calculated neutron fluxes are within several percents.

The data in the Tables 3 and 4 show that the discrepancy between measured and calculated ratios of the integral fluxes - spectral indices and attenuation factors - is approximately the same in the calculations with three libraries. The spectral indices are mainly overestimated, the attenuation through water is overestimated, and the attenuation through iron (RPV model) is underestimated. 


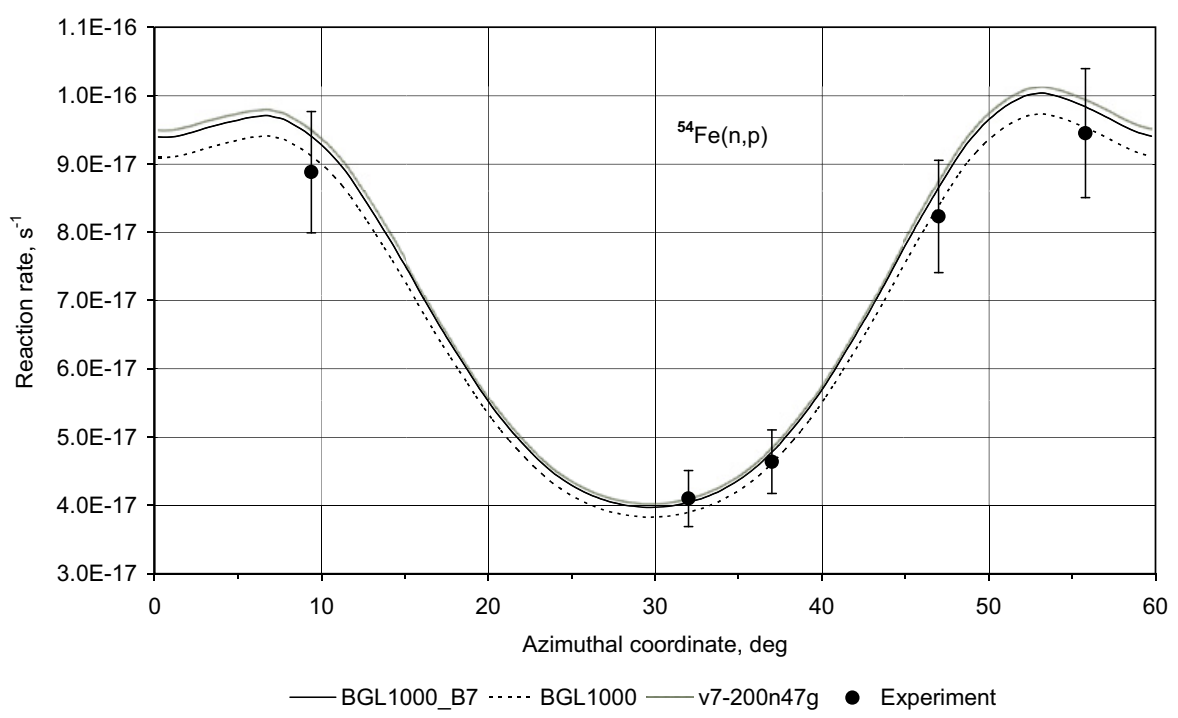

Figure 5. Azimuthal distributions of ${ }^{54} \mathrm{Fe}(\mathrm{n}, \mathrm{p})$ reaction rate at level $250.6 \mathrm{~cm}$ from the bottom core boundary.

\section{Calculation of Dosimetry Reactions Rates on the Outer Surface of the Balakovo-3 VVER-1000 Pressure Vessel}

The calculation of dosimetry reactions rates, which were measured on the outer surface of the Balakovo 3 VVER-1000 pressure vessel [7], was carried out with the KATRIN 2.0 code [5] and libraries v7200n47g, BGL1000_B7, and BGL1000. The scattering anisotropy was described in $\mathrm{P}_{3}$ approximation. The $\mathrm{ES}_{16}$ quadrature was used for $\mathrm{E}<3.0 \mathrm{MeV}$ and $\mathrm{ES}_{8}$ - for $\mathrm{E}>3.0 \mathrm{MeV}$. The pin-by-pin source with ${ }^{235} \mathrm{U}$ fission spectrum and $2.437 \times 10^{20} \mathrm{~s}^{-1}$ normalization was given in the core.

Some results are presented in the Figs. 5-7. $2 \sigma$ errors are shown for experimental data. The uncertainty of the calculation results is less than ten percents.

The shape of the azimuthal distributions depends on the core geometry (see Fig.1): the maximal reaction rates are located in front of the fuel assembly, which is closest to the pressure vessel.

All calculated data agree with measured ones within the experimental and calculation uncertainties.

\section{Evaluation of Applicability}

Two series of calculations were carried out for evaluation of applicability area of BGL1000_B7 library: neutron flux calculation at different axial levels in VVER-1000 model (Fig. 2) and neutron flux calculation in the VVER-1000 type reactor model with a $5 \mathrm{~cm}$ wider downcomer and a more thicker $(20 \mathrm{~cm})$ RPV.

Results of the first calculation are presented in the Table 5.

Results of the second calculation are presented in the Table 6.

These data show that deviations of the calculations with the broad-group libraries are higher in the regions above and down of the core. The reason is that the broad-group cross sections were generated using the neutron spectra obtained in the 1D model (Table 1) which corresponds to the core middle level.

Comparison of the data from the Tables 2 and 6 shows that the deviations of the broad-group calculations are higher in case of the increased width of the downcomer and thickness of the RPV. 


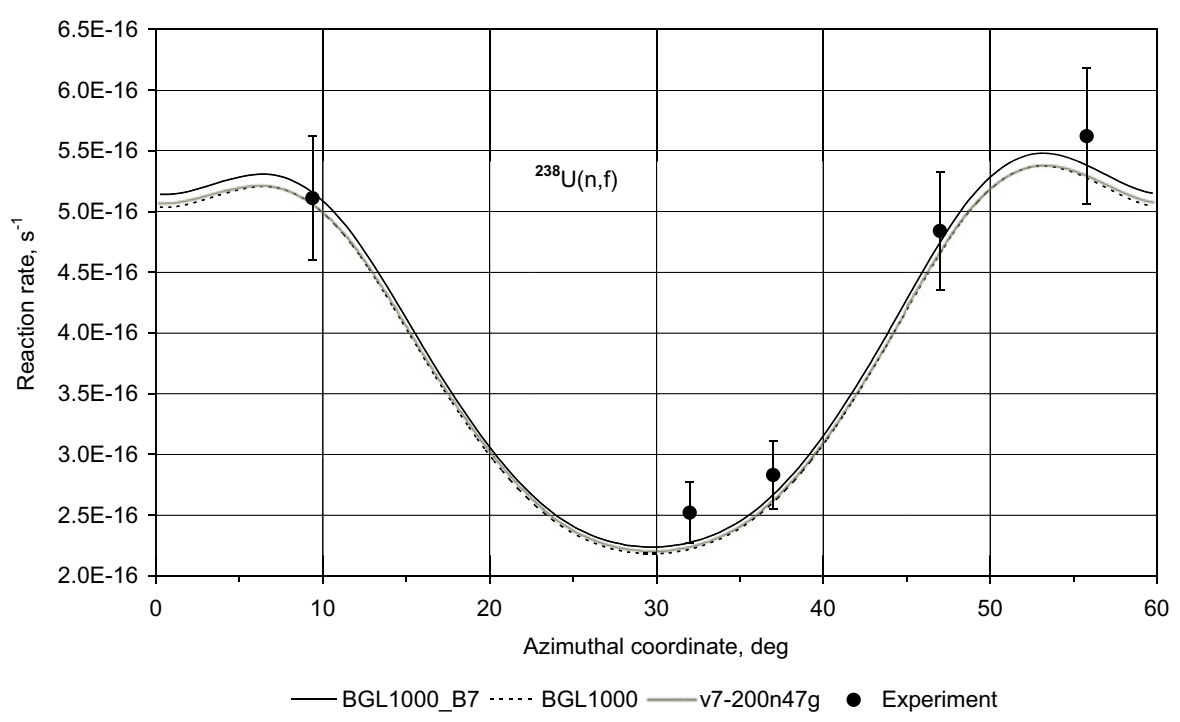

Figure 6. Azimuthal distributions of ${ }^{238} \mathrm{U}(\mathrm{n}, \mathrm{f})^{137} \mathrm{Cs}$ reaction rate at level $250.6 \mathrm{~cm}$ from the bottom core boundary.

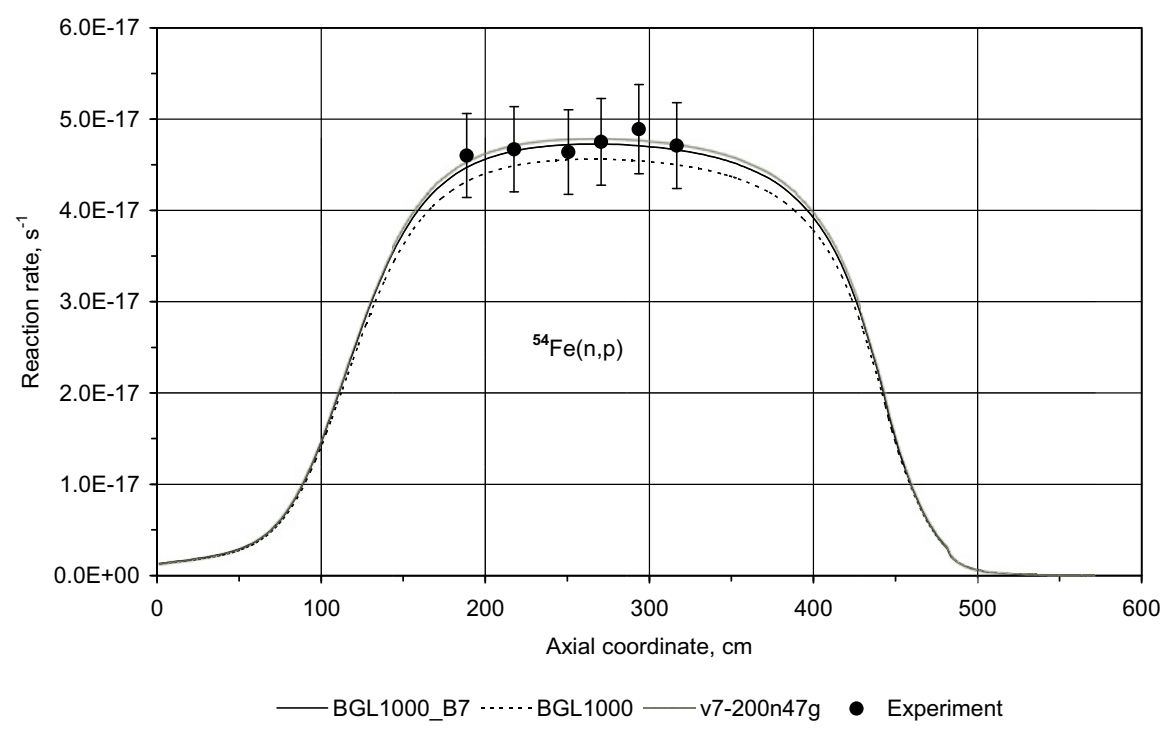

Figure 7. Axial distributions of ${ }^{54} \mathrm{Fe}(\mathrm{n}, \mathrm{p})$ reaction rate at azimuth coordinate $37 \mathrm{deg}$.

The reason is that the broad-group cross sections were obtained using the neutron spectra of the 1D model of the VVER-1000 reactor (Table 1) with other dimensions of the downcomer and of the RPV.

\section{Discussion}

As would be expected, in comparison with BGL1000 the library BGL1000_B7 provides in the region between welds No. 3 and No. 4 levels (Tables 2 and 5) better agreement with fine-group calculation based on ENDF/B-VII.0 files (library v7-200n47g). 
Table 5. Comparison of neutron fluxes obtained with three libraries at different axial levels of the VVER-1000 (axial coordinate is counted from the bottom boundary of the core).

\begin{tabular}{|c|c|c|c|c|c|}
\hline \multirow{3}{*}{ Radial region } & \multirow{3}{*}{ Axial level } & \multirow{3}{*}{$\mathrm{Z}, \mathrm{cm}$} & \multicolumn{3}{|c|}{ Library } \\
\hline & & & $\mathrm{v} 7-200 \mathrm{n} 47 \mathrm{~g}$ & BGL1000_B7 & BGL1000 \\
\hline & & & $\begin{array}{l}\text { Max. neutron flux above } \\
0.5 \mathrm{MeV}, \mathrm{cm}^{-2} \mathrm{~s}^{-1}\end{array}$ & Deviation, \% & Deviation, \% \\
\hline \multirow{6}{*}{ RPV inner surface } & Upper region & 467.9 & $3.54 \mathrm{E}+06$ & -4.8 & -10.4 \\
\hline & Weld No. 5 & 409.3 & $5.32 \mathrm{E}+08$ & -1.5 & -3.4 \\
\hline & Weld No. 4 & 295.5 & $3.49 \mathrm{E}+10$ & -0.7 & -2.4 \\
\hline & Weld No. 3 & 81.5 & $3.96 \mathrm{E}+10$ & -0.8 & -2.4 \\
\hline & Weld No. 2 & -74.1 & $4.38 \mathrm{E}+07$ & -2.5 & -8.5 \\
\hline & Lower region & -97.2 & $1.22 \mathrm{E}+07$ & -3.6 & -10.5 \\
\hline \multirow{6}{*}{ RPV outer surface } & Upper region & 467.9 & $1.13 \mathrm{E}+06$ & -9.8 & -17.6 \\
\hline & Weld No. 5 & 409.3 & $1.39 \mathrm{E}+08$ & -2.1 & -6.8 \\
\hline & Weld No. 4 & 295.5 & $5.25 \mathrm{E}+09$ & -1.4 & -4.1 \\
\hline & Weld No. 3 & 81.5 & $5.80 \mathrm{E}+09$ & -1.7 & -4.4 \\
\hline & Weld No. 2 & -74.1 & $2.61 \mathrm{E}+08$ & +3.9 & +0.3 \\
\hline & Lower region & -97.2 & $1.78 \mathrm{E}+08$ & +6.9 & +3.1 \\
\hline
\end{tabular}

Table 6. Libraries comparison in case of increasing width of the downcomer and of the RPV thickness.

\begin{tabular}{|c|c|c|c|c|c|c|}
\hline \multirow{4}{*}{$\mathrm{E}, \mathrm{MeV}$} & \multicolumn{6}{|c|}{ Library } \\
\hline & \multicolumn{3}{|c|}{ RPV inner surface } & \multicolumn{3}{|c|}{ RPV out surface } \\
\hline & v7-200n47g & BGL1000)_B7 & BGL1000 & v7-200n47g & BGL1000_B7 & BGL1000 \\
\hline & Max. flux, $\mathrm{cm}^{-2} \mathrm{~s}^{-1}$ & Deviation, $\%$ & Deviation, $\%$ & Max. flux, $\mathrm{cm}^{-2} \mathrm{~s}^{-1}$ & Deviation, $\%$ & Deviation, \% \\
\hline$>3$ & $2.87 \mathrm{E}+09$ & -3.28 & -7.08 & $8.58 \mathrm{E}+07$ & -3.69 & -7.23 \\
\hline$>1$ & $9.20 \mathrm{E}+09$ & -3.02 & -4.85 & $6.46 \mathrm{E}+08$ & -3.03 & -4.97 \\
\hline$>0.5$ & $1.38 \mathrm{E}+10$ & -2.90 & -4.43 & $2.15 \mathrm{E}+09$ & -4.19 & -6.76 \\
\hline$>0.1$ & $2.03 \mathrm{E}+10$ & -2.42 & -3.60 & $5.30 \mathrm{E}+09$ & -3.43 & -5.53 \\
\hline
\end{tabular}

All libraries give approximately the same discrepancy from experimental values measured in the VVER-1000 mock-up on the LR-0 reactor (Fig. 4, Tables 3 and 4). All calculations overestimate spectral indices (except SI 1/3 on the outer surface of RPV model), and neutron fluxes attenuation through the downcomer and underestimate them through the RPV model.

Also all calculations agree (taking into account the experimental errors) with the measurements of the ${ }^{54} \mathrm{Fe}(\mathrm{n}, \mathrm{p})$ and ${ }^{238} \mathrm{U}(\mathrm{n}, \mathrm{f}){ }^{137} \mathrm{Cs}$ reaction rates on the Balakovo-3 VVER-1000 RPV outer surface (Figs. 5-7).

The use of fine-group cross-sections is preferable for neutron flux calculations in the regions over the level of the weld No. 4 and below the level of the weld No. 3 of the VVER-1000 (Table 5) as well as in calculations of the VVER-1000 type reactors with enlarged downcomer and RPV. In other cases the special problem-oriented broad-group libraries have to be developed.

So, the realized work allows modernizing a nuclear data base of dosimetry calculations for the VVER-1000 reactors.

\section{References}

[1] J.E. White, D.T. Ingersoll, C.O. Slater, R.W. Roussin, RSICC, DLC-185 (1996)

[2] J. Bucholz, S. Antonov, S. Belousov, IAEA, INDC(BUL)-15 (1996)

[3] J.E. White, R.Q. Wright, D.T. Ingersoll, R.W. Roussin, N.M. Greene, and R.E. MacFarlane, Proc. of the Intemational Conference in Nuclear Data for Science and Technology, ORNL, pp. 733-736, (1995) 


$$
15^{\text {th }} \text { ISRD }
$$

[4] "SCALE: A Modular Code System for Performing Standardized Computer Analyses for Licensing Evaluation", Version 6, RSICC, CCC-750 (2009)

[5] "CNCSN 2009: One-, Two- and Three-Dimensional Coupled Neutral and Charged Particle Discrete Ordinates Parallel Multi-Threaded Code System”, RSICC, CCC-726 (2009)

[6] B. Ošmera, S. Zaritsky. SINBAD-LR0-VVER 1000 Radiation Field Parameters for Pressure Vessel Monitoring in VVER-1000 Using the NRI LR-0 Experimental Reactor. NEA DATA BANK, NEA $-1517 / 82$

[7] G. Borodkin, B. Boehmer, K. Noack, N. Khrennikov. SINBAD-BALAKOVO-3 Ex-Vessel Neutron Dosimetry Benchmark. NEA DATA BANK, NEA - 1517/65 